\title{
O Parmênides e as doutrinas não-escritas de Platão: o Uno e o Outro
}

\author{
The "Parmenides" and the unwritten doctrines of Plato: the One and the Other
}

\author{
Dennys Garcia Xavier ${ }^{\mathrm{I}}$
}

Resumo: Diz Cornford (em seu Plato and Parmenides: Way of truth and Plato's Parmenides) que o diálogo Parmênides inicia "a série das obras nas quais Platão pela primeira vez confronta a sua própria doutrina com os principais sistemas dos predecessores e a submete a um exame crítico" ( $\mathrm{p}_{\mathrm{i}}$ 63). Sim, mas é ainda mais: a reconstrução do diálogo à luz do método hermenêutico de Tübingen-Milão nos leva a colher a estrutura na qual se entrecruzam as visõ̃es ontológicas em três níveis, do mundo físico às Ideias e das Ideias aos Princípios primeiros. $\mathrm{O}$ elemento-chave do desenvolvimento estrutural não apenas teorético, mas também dramático, é o vínculo que se interpõe entre as duas partes do diálogo. Apenas a unidade entre as duas partes torna plausível e justificável o percurso dialético registrado no texto, como tentar-se-a evidenciar. A primeira parte do Parmênides traz a teoria das Ideias, mas abre mão de uma protologia. Não obstante isso, uma visão completa do texto põe em jogo o Uno e o/s Outro/Outros, fundamentos dos Princípios supremos. Buscar-se-á trazer à luz aqui os nexos estruturais da argumentação que nos leva a uma visão totalizante da realidade em Platão.

Palavras-chave: Parmênides; Platão; Doutrinas não-escritas

Abstract: Cornford (in his Plato and Parmenides: Way of truth and Plato's Parmenides) says that the Parmenides dialogue begins "the series of works in which Plato for the first time confronts his own doctrine with the main systems of his predecessors and submits them to a critical examination "(p.63). Yes, but it is even more so: the reconstruction of the dialogue in the light of the hermeneutic method of Tübingen-Milan leads us to gather the structure in which the ontological vision on three levels intersect, from the physical world to the Ideas and from the Ideas to the First Principles. The key element of structural development is not only theoretical but also dramatic, it is the link between the two sides of the dialogue. Only the unity between the two parts makes the dialectical course recorded in the text plausible and justifiable. The first part of Parmenides brings the theory of Ideas but gives up a Protology. Nevertheless, a complete view of the text brings into play the One and the Other/Other, foundations of the supreme Principles. The aim here is to bring to light the structural links of argument that leads us to a totalizing view of reality in Plato.

Keywords: Parmenides; Plato; Unwritten doctrines

\section{Um breve histórico metodológico}

O longo e tormentoso histórico de interpretação do Parmênides deixa claro o desafio lançado ao seu leitor: estamos diante daquele que talvez seja o mais intrincado diálogo do nosso filósofo. Maurizio Migliori, um dos seus mais autorizados tradutores/estudiosos, chega mesmo a dizer que "se quiséssemos estabelecer qual é o diálogo menos apreciado por aqueles que amam Platão, certamente o Parmênides venceria a competição" e que "trata-se da obra mais incompreendida, a mais instrumentalizada e a mais detestada" do seu corpus escrito. Não sem efeito, já os Neoplatônicos encontram nele a expressão máxima das verdades metafísicas (fase plotiniana) e teológicas (fase de Proclo) do filósofo, e, então, a sua

${ }^{1}$ MIGLIORI, Dialettica e Verità: Commentario filosofico al "Parmenide" di Platone, p. 489.

${ }^{\mathrm{I}}$ Professor de Filosofia na Universidade Federal de Uberlândia, Uberlândia, MG. E-mail: dennysgx@gmail.com. Orcid-ID: https://orcid.org/oooo-0002-9954-9815 
summa metafísica (uma impostação que se fez sentir por quase dois mil anos). Para eles, de modo geral, é possível fazer derivar das quatro primeiras teses positivas as hipóstases, enquanto que as quatro negativas levam à impossibilidade mesma de negar o Uno. Estamos evidentemente diante de uma interpretação mais teorética do que histórica, mas, nem por isso, pouco importante (note-se, por exemplo, a vasta adesão contemporânea de vertentes de tal leitura). Hegel, por sua vez, o considera a obra fundamental da dialética platônica. Ele considera, como os Neoplatônicos, que o Uno parmenideano seja o Absoluto. No entanto, exatamente por isso, considera as teses positivas e negativas contraditórias, o que, em última instância, confirmaria a impossibilidade de o intelecto alcançar o conhecimento do Absoluto, atribuindo assim à Razão a capacidade de superar as contradições do intelecto. Para Berti esses dois modelos hermenêuticos condicionaram, em diversas medidas, todas as outras propostas, com exceção das reducionistas obviamente. Para ele, as interpretações modernas

consideram as hipóteses (ou teses) do Parmênides [...] como todas positivas, vale dizer, que levam a consequências aceitáveis, ou todas negativas, que levam a consequências contraditórias, ainda que cada uma daquelas interpretações se caracterize pelos diversos significados atribuídos a essas positividade e negatividade ${ }^{2}$.

Temos ainda interpretações que tendem a problematizar o diálogo, segundo as quais o Parmênides estaria mais para uma obra antimetafísica ou, então, não construtiva, autocrítica ou simplesmente polêmica ${ }^{3}$. De resto, temos um pouco de tudo, no interior de um arcabouço hermenêutico que poderíamos denominar "reducionista/extremista": autores que vão considerá-lo obra irracional, cética, mero jogo de redução ao absurdo da lógica monista e até mesmo um simples exercício sofístico. Sobre o Parmênides, em especial, como se vê, temos sabores para todos os paladares, dos mais rústicos aos mais refinados.

O ponto relevante aqui é: nenhuma das vertentes interpretativas mencionadas levou em consideração aspectos doutrinários e metodológicos que, no interior da assim denominada escola de Tubingen-Milão ${ }^{4}$, consideramos centrais. Longe de abrir mão de um confronto criterioso com a letra do texto platônico, esta proposta hermenêutica se abre a uma nova leitura sua, inspirada também em documentos doxográficos e em autotestemunhos do filósofo, que se nos apresentam, ainda que de modo não exaustivo/completo, os eixos de sustentação de doutrina que constituía a protologia nãoescrita de Platão, um momento fundamental que nos permite reconstruir em boa medida seu sistema filosófico, integrando, em quadro minimamente unitário e coeso a investigação metafísica registrada nos diálogos.

Chamamos de "protologia platônica" os elementos doutrinários que decorrem da apreciação crítica e cruzada das assim denominadas "tradição direta" e "tradição indireta" de Platão, vale dizer: os seus textos escritos, por um lado, e a doxografia dedicada ao seu pensamento, por outro 5 .

\footnotetext{
${ }^{2}$ BERTI, Struttura e significato del Parmenide di Platone, p. 527

${ }^{3}$ Por exemplo, COLLI, . La Goliardica Pisa 1950

${ }^{4}$ Cfr. MIGLIORI, La scuola di Tubinga-Milano per una nuova immagine di Platone, p. 121-142

${ }^{5}$ Sobre este ponto, cfr. XAVIER, Para uma metafísica platônica à luz da "Tradição Indireta"; Para uma leitura alternativa de Platão; A República de Platão e as operações henológicas da Idéia de Bem e Como não ler Platão!
} 


\section{Elementos definidores do Uno.}

De fato, a fronteira porosa observada entre aquelas tradições revela, fundamentalmente, três aspectos relativos ao Uno: um axiológico, um gnosiológico e um ontológico $^{6}$

i) axiológico na medida em que o Uno é princípio, fundamento e causa de toda ordem, de toda harmonia, de justiça e de beleza - unidade na multiplicidade -, sem que seja, ele mesmo, nada disso, porque, ontologicamente, as antecede e funda;

ii) gnosiológico porque o Uno é princípio de saber, de cognoscibilidade, pois ele "determina” as coisas e a sua essência e, por via de consequência, as torna cognoscíveis (sem que seja, ele mesmo, objeto de conhecimento discursivo, na medida em que está para além daquilo que pode ser conhecido e, então, na medida em que é fundamento do que é cognoscível);

iii) ontológico porque o Uno é causa de ser, de essência e, então, confere existência a cada uma das coisas, determinando-as ontologicamente. Assim, devido ao estatuto ontológico diferenciado que o caracteriza, o princípio unitário da realidade não é suscetível de qualquer tipo de juízo apofântico e, então, não pode ser analisado segundo aquelas regras lógicas da não-contradição e do terceiro excluído. Como fundador e causador da realidade, ele antecede tudo o que é passível de tal análise e está, segundo o próprio Platão, para além de todo ser (na célebre formulação da República, "epekeina tes ousias"). Ademais, o uso de termos que evocam a noção de temporalidade e geração para analisar o papel exercido pelo Uno ("causar”, "decorrer", "fundar", por exemplo) torna-se meramente analógico e prototípico, pois, no caso em questão, apresentam a uma inteligência que trabalha de forma notadamente discursiva e analítica um processo que deve ocorrer de maneira aprocessual e não-temporal. Pela mesma razão, a estrutura hierárquico-ontológica resultante da composição entre informações extraídas dos diálogos ${ }^{7}$ e do catálogo da tradição indireta não deve implicar necessariamente uma representação espacial determinada (princípio acima das formas ideadas, etc.) - recurso que, no limite, tende meramente a aclarar o curso geral da exposição. Eis, com efeito, à guisa de remate, uma visão esquemática e resumida dos argumentos que apontam para o que afirmamos ser uma "polivalência funcional” do Uno platônico, tal como registrada nas páginas emblemáticas da República:

\footnotetext{
${ }^{6}$ Distinção exemplarmente explorada por KRÄMER, Platone e i fondamenti della metafisica

${ }^{7}$ As criptocitações extraídas de outros diálogos reforçam de maneira decisiva a teia conceitual que põe em jogo - mercê da situação ficcional criada pelo autor e do logos que determina a impostação do diálogo -, em maior ou menor grau de explicitação, a polifuncionalidade protológica da Idéia de Bem (cfr., por exemplo, a propósito do aspecto axiológico, o Górgias, 504 a 3 ss., 506 d 5 ss., o Simpósio, 186 a - 188 e, que põem a beleza, da qual o Bem é causa, como forma de ordem e de proporção - unidade na multiplicidade; o Parmênides, que, em relação ao aspecto ontológico, introduz uma solução intermediária entre aquela dos monistas (do Unotudo) e a dos Pluralistas, por meio de uma estrutura dualística universal na qual a Unidade é posta em relação bipolar com uma multiplicidade, na forma de implicação recíproca da qual tudo que existe se origina; o Filebo, diálogo no qual se parte "rumo à casa do Bem" (61 a-c) - mais um recurso teatrográfico de retração do discurso filosófico - para concluir que ele é, não como uma Ideia, algo com a natureza de causa de beleza, proporção e verdade (65b), entre outros, igualmente significativos, que, para não alargar o discurso, não podemos nem mesmo referir nesta sede.
} 
a) a ciência do Uno é a mais elevada de todas as ciências e é por meio dela que as outras virtudes se tornam úteis e valiosas $(504 \mathrm{C}-505 \mathrm{a})^{8}$;

b) o Uno confere verdade aos objetos cognoscíveis [é causa de verdade] (508e);

c) o Uno dá ao sujeito que conhece o poder de conhecer [é causa do saber] $(508 \mathrm{e})$

d) na medida em que os causa, o Uno é mais belo do que a verdade e o saber (508e-509a);

e) o conceito do Uno deve ser mais elevado do que aqueles da verdade e do saber (509a);

f) assim como o Sol no mundo sensível torna os objetos visíveis e lhes garante a gênese, a alimentação e o crescimento, o Uno garante a cognoscibilidade dos objetos cognoscíveis e confere o ser e a essência de cada um deles (509b-c);

g) tomado em si mesmo, o Uno não é uma essência, pois, pela sua dignidade e potência, está acima e para além das essências (509b-c);

h) o Uno é causa de tudo aquilo que é justo, belo, senhor da verdade e da inteligência, causa de sensatez (517c);

i) o Uno é modelo de ordenação, tanto da vida pública quanto da vida particular (540a-b).

De fato, a novidade introduzida pelos relatos exteriores dos testimonia talvez consista exatamente numa tentativa platônica de justificação radical última da multiplicidade geral em função daquele princípio, segundo um esquema meta-ontológico para além de tudo o que é. Caso contrário, como seria possível sustentar as Ideias como plano último de fundamentação metafísica se sua multiplicidade, em esfera ontológica superior, se equivale à das coisas sensíveis que, supõe-se, devem unificar? Se, como é particularmente conhecido, a pluralidade das coisas sensíveis deve ser reduzida à unidade da Ideia correspondente, de igual maneira, a pluralidade das Ideias, neste caso, é deduzida de uma estrutura que a antecede e funda, num ulterior nível de fundação metafísica. Com uma protologia, Platão teria podido sustentar com igual eficácia, tanto a pluralidade das coisas sensíveis quanto a das Ideias correspondentes (as quais, sem o nível superior de explicação, não seriam suficientemente resolvidas) ${ }^{9}$.

\section{Elementos definidores de um Princípio disteleológico.}

Depois, envolve a protologia platônica um princípio oposto ao Uno. Sobre ele muito se ouve falar também nas obras escritas e nos registros indiretos. Sabe-se pelo Timeu, por exemplo, que a geração desse universo se produziu como mistura constituída por uma combinação de Necessidade e inteligência (47e-48a). E dado que a inteligência prevalece sobre a Necessidade pelo fato de persuadi-la e por conduzir para o ótimo a maior parte das coisas que se geram, deste modo e por essas razões, por meio da Necessidade vencida pela persuasão inteligente, foi constituído desde o início o universo. Portanto, se alguém quer dizer efetivamente como ele veio-a-ser, deve introduzir também a causa errante (planoménes eîdos aitías) e tudo o que a sua natureza comporta. Estamos diante de um

\footnotetext{
${ }^{8}$ A tradução do grego e das outras línguas modernas é de quem escreve. No caso específico de Platão, utilizamos o texto estabelecido na edição crítica de BURNET, J., Platonis Opera. Oxford University Press. Quando necessário, consultamos a tradução para o italiano, Platone, Tutti gli Scritti, organizada por G. Reale e a tradução para o inglês, Plato: Complete Works, organizada por John M. Cooper.

${ }^{9}$ XAVIER, Epékeina tês ousias: o Uno-Bem na República de Platão; SZLEZÁK, La Repubblica di Platone: I libri centrali.
} 
princípio disteleológico, material, que sofre ação coercitiva - determinadora, unificante, harmonizadora - para que o universo seja produzido. De fato, não deve surpreender a semelhança descritiva/operacional entre necessidade e Díade do grande-e-do-pequeno, tal como relatada na tradição indireta ${ }^{10}$. Pouco depois de apresentar o novo elemento da sua cosmologia - a Necessidade - Platão sublinha uma vez mais a dificuldade de explicar o que ele pensa acerca do princípio ou dos princípios das coisas, "com respeito ao método da presente exposição". Trata-se, ao que tudo indica, da mesma preocupação manifestada acerca do Bem na República, uma preocupação que, de modo inequívoco, dá margem à suposição de que o nosso filósofo tenha de fato optado por não escrever sobre o que considerava ser os princípios (ao menos em termos definitivos e que, então, o tenha feito apenas de modo criptografado).

Necessidade, causa errante e receptáculo e nutriz de tudo o que devém: os termos de "aproximação" ao substrato material de todas as coisas se multiplicam nos documentos platônicos e nos textos deles derivados. Parece-nos claro que o primeiro desses termos signifique o indeterminado, o inconstante, o anômalo, isto que não pode ser nem entendido nem predito, e que nada tenha a ver com o moderno sentido normalmente atribuído à palavra (fixidez, permanência, algo inalterável).

O sentido de "receptáculo e nutriz de tudo o que devém", ao que tudo indica, é, por sua vez, elucidado pelo próprio Platão no passo que segue:

De qualquer desses corpos [que compõem o universo material] é difícil dizer qual verdadeiramente deve ser denominado água, não fogo, e qual deveremos chamar por um determinado nome, em vez de empregar todos ao mesmo tempo ou um nome de cada vez, a fim de nos expressarmos de maneira segura e digna de confiança. Em que termos, então, e de que modo exporemos essa matéria, e que dificuldade devemos, desde o início, reconhecer? Para começar, vemos perfeitamente que o que denominamos água, ao condensar-se, segundo cremos, vira pedra e terra, e ao fundir-se e dissolver-se, esse mesmo corpo se transforma em vento e ar; o ar vira fogo quando se inflama e, por um processo inverso, o fogo, contraído e extinto, retoma a forma do ar, como o ar, tornando a reunir-se e condensar-se, vira nuvem e neblina, das quais, outra vez, comprimidas ainda mais, deflui a água, para desta, de novo, sair terra e pedra (...). Então, a ser assim, se nenhum deles não se mostra nunca sob a mesma forma (oudépote tôn autôn hekáston phantadzoménon), de qual poderá alguém afirmar com segurança que é tal coisa e não outra, sem se envergonhar de si mesmo? Não é possível. O mais seguro será exprimir-nos da seguinte maneira: sempre que virmos uma coisa mudar continuamente de estado (aei hò kathorômen állote állei gignómenon) - o fogo, por exemplo - em nenhuma circunstância devemos dizer que se trata deste fogo, mas do que apresenta tais e tais qualidades do fogo; nem da água, como esta água, mas como possuidora de suas qualidades, nem nos refiramos a nada como permanente, como fazemos sempre que os designamos pelas expressões esta ou aquela (tóde kai toûto), no pressuposto de que indicamos algo definido (deloûn hegoúmethá ti) (49 b $2-\mathrm{e} 2)$

Ora, Platão se refere às coisas que a necessidade acolhe como imagens de um modelo eterno que é sempre. As imagens que imitam o que é sempre não são permanentes como o

\footnotetext{
10 "Platão caracteriza o princípio material com toda uma série de conotações, de caráter amplamente ontológico ou gnosiológico, acrescentando também uma série de imagens analógicas, algumas das quais muito belas; mas não chega às últimas conclusões" (REALE, Para uma nova interpretação de Platão, p. 449).
} 
modelo a partir do qual são construídas, mas seres que não escapam à constante força do devir, da geração e da temporalidade: cópias que mudam incessantemente e sobre as quais não podemos formular mais do que opiniões alicerçadas nas percepções sensoriais. É devido a essa natureza mutável de tudo o que compõem o universo físico, que Platão assevera a impossibilidade de afirmarmos que tal coisa seja "isto" ou "aquilo" sem nos arriscarmos a emitir parecer errado sobre a realidade. Neste mundo dos sentidos, tudo o que nos resta é a opinião "por semelhança", isto é, um tipo de julgamento que não diz o que a coisa seja de fato, mas que sugira que tal coisa se assemelhe a "isto" ou a "aquilo" num dado momento. Dizer que isto é água ou que é fogo, em acepção ontológica forte, não se harmoniza com o caráter incerto dos fenômenos físicos. Por isso, continua Platão, o "isto" ou o "aquilo" só podem se referir àquilo que subjaz todos os seres que mudam e no qual eles são plasmados, o receptáculo. A nutriz de todos os seres físicos é a única coisa que permanece (ainda que uma permanência de indeterminação) no mundo físico, uma verdadeira "matéria-prima" que se deixa moldar em infinitas formas, em infinitas imagens. E o modo como isso ocorre nos explica o próprio Platão:

Suponhamos que alguém modelasse com ouro figuras das mais variadas formas, sem parar de passar de uma forma para outra, e, ao mostrar a outro uma dessas figuras, se essa pessoa lhe perguntasse o que era aquilo, a resposta mais próxima da verdade seria declarar que é ouro (makrôi pròs alétheian asphaléstaton eipeîn hóti khrusós), pois não fora lícito falar do triângulo ou de qualquer outra figura formada com aquele mesmo material como de seres realmente existentes (hos ónta), pois todas aquelas formas se modificam (metapíptei) no próprio instante em que são apresentadas. Bastanos poder afirmar com certo grau de certeza que são possuidoras de tais e tais qualidades (tò toioûton met'asphaleías ethèlei dékhesthaí tinos). O mesmo se diga da natureza que recebe todos os corpos (tês tà pánta dekhoménes sómata phýseos): deve ser designada como a mesma, pois jamais se despoja de seu próprio caráter; recebe sempre todas as coisas, sem nunca assumir, de maneira alguma, o aspecto do que entra nela (dékhetaí te gàr aè tà pánta, kaì morphèn oudemían potè oudeni tôn eisiónton homoían eílephen oudamêi oudamôs). Por natureza, é matriz de todas as coisas (ekmageîon gàr phýsei panti keîtai); movimenta-se e diversifica-se pelo que entra nela, razão de parecer diferente, conforme as circunstâncias. Quanto às coisas que entram e saem (eisiónta kaì eksiónta), devem ser consideradas cópias das que são sempre (tôn ónton aè mimémata), cunhadas sobre esse modelo, por maneira admirável e difícil de explicar (dúsphraston kai thaumastón) (50 a 5 - c 6).

A metáfora do ouro desenha de modo irretocável tanto a natureza quanto o agir deste terceiro gênero que compõe o universo, um substrato amorfo, matéria de tudo o que devém. Não obstante isso, é preciso dizer que a necessidade não pode ser entendida como pura disteleologia, isto é, como acaso ( $t y ́ c h e)$ em grau absoluto. Fosse assim, o receptáculo seria total irracionalidade e, neste caso, jamais seria persuadido pela inteligência que a domina e com a qual compõe o cosmos. De fato, só pode ser persuadido aquele que, malgrado múltiplas diferenças com o parceiro, concorda com ele em certa medida. Aqui, alude-se manifestamente ao fato de que os dois Princípios (noûs-anánke), permanecendo em fundamental oposição, podem ser referidos um ao outro, se devem, em geral, agir juntos ${ }^{11}$.

O "princípio anipotético" (arkhén anypótheton), por sua vez, é princípio formal supremo, causa de verdade, de cognoscibilidade, de poder de conhecer, de beleza, de

${ }^{11}$ HAPP, Studien zum aristotelischen Materie-Begriff. 
sensatez, de justiça e inteligência - sem ser, ele mesmo, nada disso de que é causa. Assim, se o agir henológico é condicionado por alguma coisa, definitivamente não pode ser por algo que o anteceda - dado que nada é antes dele -, mas, no limite, pela natureza do princípio material que se lhe antepõe, qual seja, a Díade. Seja isto correto, podemos sim compreender, em termos prototípicos e analógicos, o proceder demiúrgico a partir do Uno-Bem - ambos como "causas formais" e "eficientes" em seus respectivos planos de atuação -, desde que seja feita ressalva concernente à natureza ontológica de cada um: só o Demiurgo contempla um modelo - porque dele depende - para agir, enquanto que o Uno-Bem é ele mesmo, na medida em que imprime sua forma no princípio oposto, modelo e causa eficiente do que dele é predicado.

Aristóteles chama a Díade platônica de "elemento de todos os seres", matéria que tem a função de substrato tanto dos seres sensíveis quanto das Ideias. Há mais, porém. Num outro texto de Simplício - citando Eudemo - a Díade vem diretamente associada ao movimento caótico atribuído à necessidade. Leiamos o texto e, em seguida, o trecho correspondente do Timeu:

[...] Eudemo, antes de Alexandre, examinando a opinião de Platão sobre o movimento, e opondo-se a ela, escreve: "Platão diz que o movimento é o grande-e-opequeno, o não-ser, o anômalo e tudo o que conduz ao mesmo com relação a estes (tò méga kaì mikròn kai tò mè òn kai tò anómalon kaì hósa toútois epi tautò phérei tèn kínesin légei). Mas dizer que justamente isso é movimento parece absurdo: de fato, quando existe movimento, parece que se move aquilo no qual ele existe. Mas é ridículo dizer que, existindo o desigual e o anômalo (anísou dè óntos è anomálou), é necessário que se movam. De fato, é melhor dizer que essas coisas são causas (aítia), como diz Arquita". E, pouco depois, ele acrescenta: "Os pitagóricos e Platão reconduzem, por boa razão, o indefinido ao movimento (tò aóriston/epì tèn kínesin)" $[\ldots]$.

E Platão:

Ora, nutriz da geração (genéseos tithénen) umedecida e inflamada, acolhendo em si as formas da terra e do ar, e passando por todas as modificações que se lhes seguem, mostrava-se infinitamente diversificada. E por estar cheia de forças que nem eram iguais nem equilibradas, não mostrava equilíbrio em nenhuma de suas partes (oudèn autês isorropeîn); oscilando irregularmente em todos os sentidos, era agitada por essas forças e, posta em movimento, por sua vez as agitava. Movimentando-se desse modo, sem pausa, separavam-se as coisas e dispersavam-se em várias direções, como ocorre com a limpeza do trigo, quando, movimentado e ventilado pelas peneiras e por outros instrumentos, as partes densas e pesadas se juntam de um lado, as partes finas e mais leves de outro [...] e, por isso, umas ocupavam um lugar e outras um lugar diferente, mesmo antes que com elas se gerasse o universo ordenado (prin kaì tò pân eks autôn diakosmethèn genésthai). E antes disso todas as coisas se encontravam sem razão e sem medida. Quando o universo começou a ser posto em ordem (kosmeîsthai), o fogo em primeiro lugar, a terra, o ar e a água já revelavam traços de sua própria natureza, mas se encontravam na condição em que é de esperar que esteja o que carece da presença de Deus (ékhein hápan hótan apêi tinos theós) $(52 \mathrm{~d} 4-53 \mathrm{~b} 4)$

A Díade, um aspecto da Necessidade, está associada a um tipo de movimento primitivo, de agitação primordial, característico do que se encontra abandonado a si mesmo: neste contexto, sem a presença antitética de uma causa ordenadora e unificante que condiciona a mistura a partir da qual, em plano ontológico superior, são concebidas as Ideias e, em plano ontológico inferior, o mundo da physis. Sobre a tal princípio, diz Aristóteles (Física, IV 2, 209 b 10-17): 
Por isto, também Platão no Timeu diz que a matéria e a espacialidade (hýlẹn kai tèn khóran) são a mesma coisa: de fato, o participante e a espacialidade (metaleptikòn kaì tèn khóran) são uma única e mesma coisa. Mas, ainda que ele defina de modo diferente o participante aqui e nas assim ditas doutrinas não-escritas, disse claramente que o lugar e a espacialidade (tòn tópon kaì tèn khóran) são a mesma coisa. De fato, todos dizem o lugar é alguma coisa (ti tòn tópon), mas o que seja, precisamente, apenas ele tentou dizer.

E ainda (Física, IV 2, 209 b 33 - 210 a 2):

Em verdade, seria necessário perguntar a Platão se nos é lícito sair do nosso discurso, por que as Ideias e os Números não estão num lugar (dià tí ouk en tópoi i), dado que o participante é o lugar (methektikòn ho tópos), quer ele seja o grande e o pequeno (toû megálou kai toû mikroû), quer ele seja a matéria (tês hýlés), como escreveu no Timeu.

Não nos interessa aqui a apropriação teorética da filosofia de Platão operada por Aristóteles, mas a referência histórica e o conteúdo objetivo que resulta dela. No primeiro passo supracitado da Física o Estagirita sublinha uma clara identificação entre matéria, espacialidade, lugar e participante - este último, segundo ele, "definido de forma diferente" nas lições não-escritas do mestre. São, muito provavelmente, formas utilizadas por Aristóteles para se referir àquele terceiro gênero aduzido por Platão para que a descrição do universo ficasse completa. De fato, tal como nos relata Aristóteles, Platão associa de forma inequívoca o terceiro gênero à espacialidade no Timeu, gênero que, definido de forma diferente, talvez tenha recebido, nas lições orais, exatamente o nome utilizado por seu discípulo no segundo trecho já citado da Física: "o grande-e-o-pequeno". Eis o texto de Platão:

[...] teremos de admitir que há, primeiro, a ideia imutável, que não nasce nem perece e que não acolhe de fora outra coisa, nem passa jamais a outra coisa, e não é visível nem perceptível de qualquer jeito, e só pode ser apreendida pelo pensamento. A outra espécie tem o mesmo nome da primeira e com ela se parece, porém, cai na esfera dos sentidos; é engendrada, está sempre em movimento, devém num determinado local, para logo desaparecer daí, e é apreendida pela opinião acompanhada pela sensação. E, por sua vez, é preciso admitir que há um terceiro gênero, o do espaço, que é sempre e não é sujeito a corrupção, que fornece uma sede a todas as coisas sujeitas à geração; e este é captável sem os sentidos com um raciocínio bastardo e dificilmente crível (tríton te én aû génos òn tò tês khóras aeí, phthoràn ou prosdekhómenon, hédran dè parékhon hósa ékhei génesin pásin. autò dè met'anaisthesías haptòn logismôi tini vóthoi, mógis pistón) (52 a 1-b 2).

Afirmar que o terceiro gênero - do espaço, da necessidade, do receptáculo ou da nutriz de tudo o que devém - é captável apenas com um "raciocínio bastardo e dificilmente crível”, ou ainda, que ele seja uma espécie "difícil e obscura” é parte do "jogo" que Platão reconhece na arte de compor um escrito.

\section{Os Princípios no Parmênides.}

Platão não trata de protologia, ao menos stricto sensu, na primeira parte do Parmênides $^{12}$. Nela temos, em linhas gerais, a proposição de três problemas relativos à própria estrutura da realidade ideal: 1) a relação entre as Ideias e, então, sobre a

${ }^{12}$ A primeira parte vai de $126 \mathrm{a}$ até 136e. A segunda parte vai de 136e até 166c 
possibilidade de vínculo entre elas (especialmente à luz do binômio UnidadeMultiplicidade); 2) a visão das Ideias em chave, por assim dizer, fisicista, todas dispostas em plano ontológico único, como seres que duplicam o real; 3) derivado do segundo, a possível separação entre Ideias e mundo dos fenômenos. Em nenhum momento, entretanto, a possibilidade mesma das Ideias é posta em dúvida ou problematizada a ponto de colocá-la sob séria ameaça. Antes pelo contrário, as dificuldades enfrentadas são apresentadas, nas palavras de Migliori, como:

[...] a marca da juventude de Sócrates, que ignora a dialética e não a praticou. Para tal tarefa é, então, convidado, com tamanho afeto que o velho Parmênides se propõe inclusive de forma fatigante a oferecer dela um exemplo concreto. É a prova de que tal exercício serve exatamente para resolver as dificuldades expostas, alçando a reflexão a um superior nível metafísico ${ }^{13}$.

Aqui se interpõe de forma decisiva uma protologia que depende de uma relação ontológica de derivação na qual o grau mais alto possui sempre um prius ôntico em relação àquele mais baixo (proteron-husteron physei) e na qual, para dizer com formulação platônica, o primeiro pode ser pensado sem o segundo, mas não, vice-versa, o segundo sem o primeiro (sunanairein kai mé sunanareistai). Tem-se, então, uma relação de dependência unilateral não reversível na qual, todavia, o plano mais alto oferece apenas condições necessárias, mas não também suficientes para o plano sucessivo. No Parmênides, então, o eixo de toda a polêmica está ancorado num sistema de nexos que devem (ou podem) ligar as Ideias ao mundo, as Ideias entre si e os Princípios às Ideias.

A primeira parte do diálogo é uma narrativa dramática, rica de interlocutores como Sócrates, Zenão e Parmênides, postos ali para delinear uma reinterpretação forçada do Eleatismo, uma mentira ficcional que seria certamente desprezada pelos mestres em cena, que tem como pano de fundo forte tensão de filosofia pré-socrática e naturalista. A segunda parte, em vez disso, não é exatamente um diálogo. Se fizermos a menos de algumas breves passagens nas quais notamos a presença de Aristóteles, temos, a bem da verdade, um monólogo de Parmênides. Naquele ponto é operada por Platão uma reinterpretação do Eleatismo, tal como registrado na primeira metade dramática da obra, por meio de um discurso pronunciado por Parmênides: um personagem estranho, que constrói uma concepção bipolar do mundo obtida por meio de investigação dialética. A passagem entre primeira e segunda parte é necessária e definitiva:

a) por que aquele proêmio, a longa viagem de Clazomenas para escutar aporias e dificuldades relativas a uma doutrina das Ideias tão grosseiramente apresentada? A única resposta convincente: a novidade que deriva do encontro (filosófico, não histórico) entre Socratismo e Eleatismo, desenvolvido na segunda parte;

b) por que a reinterpretar o Eleatismo sob os auspícios de uma relação com as Ideias, vale dizer, com os elementos que saem da boca de Sócrates? Dali surgem as condições da protologia platônica, como síntese de uma visão dialética do real, que se deixa entrever, também ela, na segunda parte do diálogo;

c) por que Parmênides exerce este papel em tudo inesperado, que o leva a aceitar, e ao mesmo tempo a atacar, as Ideias ventiladas por Sócrates, na mesma medida em que põe em xeque o inteiro Eleatismo com a formulação da hipótese do Não-Ser? A resposta parece ser: assim se apresenta a figura de Platão como alguém para além de Sócrates e para além do Eleatismo, aquela que encontramos gravada na segunda parte.

Eis, então, que são os Princípios, aqui apresentados sob o jogo do Uno e do(s) Outro(s), o coração teorético de toda a tratação do diálogo em tela. De fato, ali se articula,

${ }^{13}$ MIGLIORI, Dialettica e Verità: Commentario filosofico al "Parmenide" di Platone, p. 503. 
no diálogo, um processo de unificação (Uno-todo) e de divisão (Uno-parte) que Platão descreve na totalidade do real como "um todo completo e dotado de partes" (157e). A bipolaridade prototípica "Todo-Parte" está impressa em toda a realidade. A relação recíproca dos dois termos é dada por certa desde a primeira tese: o Todo assim é porque nenhuma Parte lhe falta e a Parte assim é porque pertence a um Todo (137c). E claro, que nada disso deve ser lido em termos fisicistas, resta confirmado na segunda tese que, ao nos oferecer um Todo composto de Ser e de Uno, nos deixa entrever uma realidade categorial (Parte com possibilidade infinita de divisão, Todo como a definição de limite) (144d-145a).

O processo que culmina no jogo Todo-Parte se erige na bipolaridade originária Uno e Díade. No início da segunda tese, Platão destaca em que medida a natureza do Uno permanece em todos os casos diversa e separada do Uno-que-é: uma coisa é o Ser uno, outra é este Uno que participa do ser. Depois, ele ressurge no passo dedicado à Diversidade, segunda tese. De início, afirma-se que o Uno, tomado em si, exclui a Diversidade (139c). Um Uno que exclui a Diversidade, e também a relação Parte-Todo, idêntico a si mesmo (146b-c). Uma espécie de Uno tomado em si mesmo, uma natureza de Uno ainda a ser definida, naquele contexto. Quanto à Díade, vem evidentemente evocada ao se falar do Não-Uno, na qual a presença inclusive da Diversidade vem completamente excluída, na medida em que aquela em nada participa do Uno (144a-b).

Se, então, tomamos os dois termos em sentido absoluto, o Uno e o Não-Uno, o Uno não será nem parte das coisas que não são Uno, nem um todo do qual são partes; por sua vez, mesmo as coisas que não são Uno não serão nem partes do Uno nem um todo do qual o Uno seja parte.

Ainda neste sentido, a afirmação da bipolaridade prototípica foi até mesmo antecipada em observação quase displicente do filósofo, mas que constitui a razão fundamental pela qual Platão abandonou um rígido monismo eleático (138b): "De fato, uma realidade na sua inteireza não poderá, ao mesmo tempo, deter a dúplice função de sofrer e fazer. De outra forma o Uno não seria mais Uno, mas dois".

As Ideias são estruturalmente unidade no múltiplo e isso é possível tão-somente porque a unidade enquanto tal se põe num nível superior em relação ao múltiplo (que é porque aquele é unificado), o que nos leva a uma arquitetônica piramidal até a origem de todas as coisas, fundamento de tudo o que existe, uma bipolaridade originária. Eis que, com base no quadro delineado/cripto-registrado pelo Parmênides, a verdadeira contradição entre Platão e Aristóteles não é aquela rafaelesca entre vertical e horizontal, mas aquela entre o jogo infinito e dialético de Platão (que nada tem a ver com o problematismo) e a atitude classificadora do Estagirita. O Parmênides constitui monumento àquele jogo e a sua inutilidade vinha assinalada com a manifestação de um total desinteresse [da parte de Aristóteles].

É o fim do argumento do "Terceiro Homem" no horizonte da filosofia platônica. Com o Parmênides os gêneros não são mais vistos como simples unidades que reúnem multiplicidade homogênea. São entidades qualitativamente distintas das próprias "partes", da qual não se gera uma multiplicidade numérica, suscetível a processo infinito de unificação.

\section{Referências}

ARISTOTELE, La Metafisica. A cura di REALE, G. Milano: Rusconi, 1994. ARISTOTELE, La Fisica. Bari: Laterza, 1968. 
BERTI, E. Struttura e significato del Parmenide di Platone. Giornale di Metafisica 26, 1971, pp. 495-527.

COLlI, G. La Goliardica Pisa 1950 (aulas do curso de História da Filosofia Antiga do ano acadêmico 1949-1950).

CORNFORD, F. Plato and Parmenides. Way of truth and Platos's “Parmenides”. London: K. Paul, Trench, Trubner \& co. Ltd., 1964. Reprinted by Routledge \& Kegan Paul, 1980.

HAPP, H. Studien zum aristotelischen Materie-Begriff, Berlim-New York, 1971.

KRÄMER, H. Platone e i fondamenti della metafisica. Milano: Vita e Pensiero, 2001.

MIGLIORI, M. Dialettica e Verità: Commentario filosofico al "Parmenide” di Platone. Milano: Vita e Pensiero, 200o.

MIGLIORI, M La scuola di Tubinga-Milano per una nuova immagine di Platone. Breve inquadramento storico dell'interpretazione platonica della scuola di Tubinga-Milano (Krämer, Gaiser, Reale, Szlezák). Il Cannocchiale Rivista di Studi Filosofici 1, 1992, pp. 121-142.

PLATO, Complete Works. Indianapolis/Cambridge: Hackett1997.

PLATO, Platonis Opera. BURNET, J. (ed.). Oxford: Clarendon, 1892-1906. (Várias edições)

PLATO, Tutti gli Scritti. REALE, G. (ed.). Milano: Bompiani, 2000.

REALE, G. Para uma nova interpretação de Platão. Trad. de Marcelo Perine. São Paulo: Loyola,1997.

SZLEZÁK, Th. A. La Repubblica di Platone: I libri centrali. Brescia: Morcelliana, 2003.

XAVIER, D.G. A República de Platão e as operações henológicas da Idéia de Bem. Síntese, Belo Horizonte, v. 34, 2007, pp. 247-26o.

XAVIER, D.G. Como não ler Platão! Revista Archai: Revista de Estudos sobre as Origens do Pensamento Ocidental, v. 6, 2011-1, pp. 93-98.

XAVIER, D.G. Epékeina tês ousias: o Uno-Bem na República de Platão. In: XAVIER, D.G.; CORNELLI, G. (Orgs.). A República de Platão: Outros olhares. São Paulo: Loyola, v. 1, 2011-2, pp. 227-238.

XAVIER, D.G. Para uma leitura alternativa de Platão. Educação e Filosofia, Uberlândia, v. 19, 2005-2, pp. 145-157.

XAVIER, D.G. Para uma metafísica platônica à luz da "Tradição Indireta". Hypnos, São Paulo), v. 15, 2005-1, pp. 117-128. 